\title{
DIFICULDADES E DESCOBERTAS DE UMA PESQUISA EMPÍRICA \\ EM DIREITO: estudo de casos a partir de documentos de arquivos judiciários // Vanessa Dorneles Schinke ${ }^{1}$
}

\section{Palavras-chave}

pesquisa empírica / direito / estudo de caso / paradigma indiciário / relato

\section{HIIIIIIIIIIIIIIIIIIIIIIIIIIIIIIIIII}

\section{Sumário:}

\section{Introdução}

2 Plano de vôo I: primeiro contato com expressões e estratégias de pesquisa empírica

3 Plano de vôo II: a necessidade de adoção da empírica e o aprofundamento sobre estratégias metodológicas

4 A exploração: a indissociabilidade do amadurecimento da reflexão teórica com a pesquisa de campo

5 Fazendo uma limonada: dando sentido aos desafios da pesquisa empírica

6 A escolha metodológica: otimizando fontes e conjugando estratégias

7 Considerações finais

8 Referências

\section{Resumo}

Este texto relata o percurso de uma pesquisa empírica em direito realizada durante o curso de doutorado da autora. Narrado em primeira pessoa, descreve as dificuldades práticas e as descobertas teóricas construídas ao longo do desenvolvimento de uma pesquisa que culminou com a opção pela estratégia metodológica do estudo de caso. Paralelamente, insere considerações teóricas sobre as escolhas metodológicas que se apresentaram durante o processo, especialmente Robert Yin e Carlo Ginzburg. Explica de que forma tal bibliografia possibilitou a combinação de várias estratégias na pesquisa, paralelas ao estudo de caso. De forma minuciosa, relata a fase de exploração, o contato com outros espaços de pesquisa e com profissionais de outras áreas. O texto não apresenta os resultados da pesquisa relatada, pois ela ainda não está concluída. Pretende contribuir para a solidificação do debate sobre a forma de produção do conhecimento jurídico. 


\section{DIFFICULTIES AND FINDINGS OF AN EMPIRICAL LEGAL \\ RESEARCH: case studies built on judicial documents // Vanessa Dorneles Schinke}

\author{
Keywords \\ empirical research / law / case study / indication \\ paradigm / report
}

\begin{abstract}
This paper describes the journey of an empirical researcher during her doctoral studies. Narrated in first person, it describes the practical difficulties and theoretical discoveries built throughout the development of the research that culminated in the methodological choice of using the strategy of case study. Similarly, it inserts theoretical considerations about the methodological choices that presented themselves during the process, especially Robert Yin and Carlo Ginzburg. It explains how these works enabled the combination of several research strategies, along with case study. It describes in detail and reports the exploratory phase, the contact with other areas of research and with professionals in other fields. The text presents the results of research reported because it is not yet completed. It aims to contribute to the solidification of the debate about production of legal knowledge.
\end{abstract}




\section{Introdução}

Este texto relata o percurso de uma pesquisa empírica iniciada durante um curso de doutorado em direito. A fim de amenizar eventuais frustrações, adverte-se, desde já, que este texto não apresenta resultados da pesquisa relatada, pois ela ainda está em curso. Naturalmente, apesar de apresentar bases teóricas sobre o objeto da investigação, a fim de contextualizar o leitor e de apresentar elementos que, consciente ou inconscientemente, revestir-se-iam de maior importância durante o transcurso da pesquisa e interferiram diretamente na estratégia metodológica adotada, o propósito maior é compartilhar os tortuosos caminhos que o pesquisador que se propõe a realizar uma pesquisa empírica em direito pode percorrer. ${ }^{2}$

Ainda que teça considerações sobre o período acadêmico que antecedeu ao doutorado, o relato tem como objetivo principal apresentar algumas dificuldades e circunstâncias inesperadas que surgiram no transcurso do processo de campo e que contribuíram para a melhor compreensão do fenômeno de pesquisa e, consequentemente, para o amadurecimento do projeto. Para tanto, convém situar o leitor, inclusive temporalmente, sobre a escolha do objeto e do problema de pesquisa.

Iniciado em março de 2012, o projeto de pesquisa de doutorado já se situava claramente na área de justiça de transição. Esse conceito é utilizado para designar uma ampla concepção de justiça, associada a mudanças políticas, destinada a enfrentar danos após um regime político repressor (Teitel, 2003, p. 72). Van Zyl (2009, p. 34) enuncia que a justiça de transição implica em processar os perpetradores, revelar a verdade sobre crimes passados, conceder reparações às vítimas, reformar as instituições perpetradoras de abuso e promover a reconciliação. Jon Elster (2006, p. 17) e Ruti Teitel (2003, p. 74) concordam que o moderno conceito de justiça de transição surge após a Segunda Guerra Mundial, quando Alemanha, Itália e Japão empregaram diversas medidas para promover algum grau de justiça em relação aos fatos da Segunda Guerra. Relevante registrar que essa concepção de justiça volta-se tanto para o passado - como no caso da elucidação de graves violações de direitos humanos e na identificação dos responsáveis -, quanto para o futuro, a fim de oferecer instrumentos que, por exemplo, permitam e indiquem a necessidade de reformas institucionais que impeçam que tais violações aconteçam novamente. 0 liame entre essa dupla projeção (passado-futuro) é construído através do desenvolvimento de políticas de memória, que constantemente ressignificam as violações ocorridas para as presentes e futuras gerações, mantendo latente a necessidade de rever os fundamentos do Estado Constitucional.

Dentro desse contexto, a pesquisa teve como problema indagar de que forma Poder Judiciário brasileiro atuou durante os anos de 1964 e 1985. Foi realizado um recorte no judiciário brasileiro, por razões operacionais, de forma que o trabalho centrou-se na atuação da justiça comum (estadual e federal) do Estado do Rio Grande do Sul. Com o desenvolvimento da pesquisa, foram elaboradas algumas variáveis teóricas aptas a comprovar que as decisões judiciais foram omissas ou apresentavam fundamentos que colaboravam com construções ideológicas do regime militar.

Importante ressaltar que a definição do problema de pesquisa ocorreu um ano após a criação da Comissão Nacional da Verdade, cujo relatório final dos seus trabalhos foi entregue à sociedade em dezembro de 2014. ${ }^{3}$ Dentre outras variáveis, isso significa que quase a totalidade do período da pesquisa foi marcado pelo desconhecimento do tema por parte das instituições contatadas durante o trabalho de campo. Essa ausência de trabalhos sobre o fenômeno contribuiu significativamente para o surgimento de diversas dificuldades ao longo da pesquisa, como a não-sistematização dos processos judiciais do período da ditadura e a ausência de instrumentos infor-

matizados para a busca nos arquivos.

\footnotetext{
2 Neste texto, as expressões pesquisa empírica em direito e/ou pesquisa empírica no campo jurídico serão utilizadas no intuito de demarcar que as reflexões teóricas do direito e, de forma geral, a produção do conhecimento jurídico podem ser ressignificadas, melhor elucidadas e/ou compreendidas quando somadas a estratégias empíricas de pesquisa.
}

\footnotetext{
3 A Comissão Nacional da Verdade foi criada pela Lei no $12.528 / 2011$, instituída em 16 de maio de 2012, tendo por finalidade apurar graves violações de direitos humanos ocorridas entre 18 de setembro de 1946 e 5 de outubro de 1988.
} 
Apesar das intempéries do processo de pesquisa empírica, relatadas a seguir, atualmente é inegável que a divulgação dos trabalhos da Comissão Nacional da Verdade - que possuiu um grupo de trabalho voltado a analisar criticamente o sistema de justiça durante a ditadura -, contribuiu para que o enfoque sobre o papel desempenhado pelo judiciário durante a ditadura ganhasse maior destaque no meio acadêmico. Consequentemente, as dificuldades expostas neste texto devem ser conjugadas com o estágio de reflexão dos espaços de produção do conhecimento jurídico sobre o próprio direito e sobre os agentes do direito e espaços de justiça. Nesse sentido, merece destaque um trecho da conclusão da Comissão Nacional da Verdade sobre as funções desempenhadas pelo judiciário brasileiro durante a ditadura civil-militar:

Destarte, sublinha-se que, em conjunto, as decisões do Poder Judiciário, quando do período ditatorial, refletem, muitas vezes, seu tempo e seus senhores; são expressões da ditadura e de seu contexto de repressão e violência. Os magistrados que ali estiveram - ou melhor, que ali permaneceram - frequentemente eram parte dessa conjuntura, inclusive porque, por meio da ditadura militar, foi-lhes garantido um assento naqueles tribunais. Quem quer que tenha sido nomeado para o STF, por exemplo, durante a ditadura, tinha clareza das circunstancias a que estavam jungidos e quais votos eram esperados da sua lavra; sabiam da ausência de garantias dos magistrados; conheciam as reformas promovidas na composição e atribuições do tribunal; e, sobretudo, eram cônscios acerca de quem deveriam servir. Nesse contexto, conclui-se que a omissão e a legitimação institucionais do Poder Judiciário em relação às graves violações de direitos humanos, então denunciadas, faziam parte de um sistema hermético mais amplo, cautelosamente urdido para criar obstáculos a toda e qualquer resistência ao regime ditatorial, que tinha como ponto de partida a burocracia autoritária do Poder Executivo, passava por um Legislativo leniente e findava em um Judiciário majoritariamente comprometido em interpretar e aplicar o ordenamento em inequívoca consonância com os ditames da ditadura (Brasil, 2014, p. 957).

Isso posto, retornando à natureza deste texto, trata- -se de um relato que faz uma análise de caso sobre o processo de amadurecimento de uma proposta de pesquisa e sobre sua própria execução. Dessa forma, excepcionalmente, é estabelecida uma metarrelação para observar o transcorrido com quem se propôs a observar fatos que conseguissem problematizar minimamente as reflexões teóricas da pós-graduação e tentar produzir conhecimento jurídico por trilhas que não compartilhassem da pretensão totalizadora dos conceitos da dogmática do direito.

No andar da carruagem, como se verá, descobriu-se que as maiores dificuldades da pesquisa empírica ocorreram em circunstâncias que não estavam previstas nos livros de metodologia do direito, ou que, embora previstas por outros autores das ciências sociais (Stake, 2009; Habermas, 2009), pareciam demasiado longínquas para um pesquisador que tem sua formação em direito atrelada a uma ideia de pesquisa que tende a replicar conceitos, no sentido de que tal reprodução (geral, abstrata e impessoal) seria a própria produção de conhecimento jurídico.

Embora não houvesse essa consciência ao tempo dos primeiros fatos aqui relatos, este relato trata, além do relacionamento entre teoria e empiria, da tensão produtiva - da qual o pesquisador pode se valer -, a fim de construir planos de ação que busquem refletir sobre o direito sem a pretensão de adotar um comportamento cartesiano, cuja concepção de que um organizado encadeamento de regras e princípios possibilitaria a apreensão do pensamento e, por que não, do universo (Baumer, 1990a, p. 56).

Ademais, a narrativa é feita em primeira pessoa, no intuito de marcar a voz ativa do pesquisador que, não casualmente, é o narrador. Essa escolha foi realizada para não esconder a riqueza da experiência decorrente de um processo de pesquisa empírica em direito em um discurso impessoal e passivo. Ao contrário, o relato tenta registrar que diversas decisões tomadas no curso da pesquisa surgiram em um contexto complexo, que uniu o meu histórico de pesquisa, a proposta de pesquisa e as situações concretas com as quais me confrontei na tentativa de produção de conhecimento. Muitas das escolhas realizadas nesse processo, então, foram ponderadas a partir de uma boa dose de sensibilidade, que não se confunde 
com ausência de critérios ou com falta de rigor metodológico. Ao contrário, esse relato reconhece que o pesquisador só consegue sustentar teoricamente determinadas decisões se conseguir estabelecer uma delicada articulação entre seu histórico de experiência e seu horizonte de expectativa (Koselleck, 2006). Essa fórmula que une razão e sensibilidade ainda não está disponível em drágeas, de forma que os livros podem alertar os pesquisadores de que, possivelmente, em algum momento, soluções metodológicas criativas poderão (ou deverão) ser adotadas, mas as doses e os momentos para isso variam caso a caso. ${ }^{4}$

\section{Plano de vôo I: primeiro contato com expressões e estratégias de pesquisa empírica}

Fiz o mestrado em uma universidade pública que tem um trabalho tradicionalmente voltado para o debate constitucional e que desenvolveu em papel fundamental na história do ensino superior brasileiro, especialmente na época da ditadura civil-militar. Além disso, a linha de pesquisa na qual ingressei era bastante receptiva a contribuições provenientes de outras áreas, afirmação que poderia ser redundante, mas que, na área do direito, merece ser registrada.

Fui apresentada à expressão estudo de caso no início do mestrado, casualmente em uma das primeiras aulas de quem viria a ser meu orientador. Passado algum tempo do início do curso, em boa parte dedicado à ambientação e à escolha, recíproca, da dupla orientador-orientanda, havíamos definido que a dissertação utilizaria um estudo de caso para verticalizar as considerações teóricas. A ideia era desenvolver o conceito de soberania, com base nas teorias da Constituição, a partir de um fato ocorrido em 2000. $\mathrm{Na}$ ocasião, o então Presidente Fernando Henrique Cardoso acionou o Exército para proteger sua fa-

4 Ainda sobre avisos preliminares ao leitor, convém registrar que, em boa parte, este texto tem como inspiração um relato de Kant de Lima (1997), posteriormente transformado em livro, em que ele descreve seus percalços durante seu período de estudante nos Estados Unidos. Embora o referido livro tenha claramente outro propósito, qual seja, o de apresentar reflexões antropológicas sobre as vivências acadêmicas norte-americana e brasileira, a naturalidade dos relatos e a escrita em primeira pessoa são, inegavelmente, elementos trazidos para este artigo. zenda, localizada em Minas Gerais, de uma eventual invasão pelos integrantes do Movimento dos TrabaIhadores Rurais Sem Terra (MST). Naquele momento, a ideia parecia-me excelente, pois meu desconhecimento metodológico sobre aquela estratégia de pesquisa inseria-me em um nível confortável de despreocupação. Além disso, o fato concreto (mobilização do exército para proteção da fazenda do Presidente da República), por si só, era bastante interessante. Instintivamente, parecia-me razoável (e suficiente) a presunção de que um caso concreto interessante resultaria em um bom estudo de caso.

Na época, minha base epistemológica sobre estudo de caso resumia-se à expressão cunhada pelo meu orientador nas suas aulas: "O estudo de caso é um guarda-chuva: ele abre, mas também impõe limites". Desconsiderando minha vivência em pesquisa (em boa parte não empírica) que vinha desde o início da graduação em direito, minhas estratégias metodológicas resumiam-se a refletir sobre essa frase - o que muitas vezes me fez pensar: "Isso entra no guarda-chuva, isso sai”. Em virtude de diversos fatores, principalmente por ter contato com outros enfoques, outras vivências e novos problemas, meu objeto da pesquisa foi alterado, motivo que afastou, temporariamente, a estratégia do estudo de caso da minha pesquisa.

A partir do segundo ano do mestrado percebi que minha dissertação seria um exercício de criatividade. Mesmo sem ter plena consciência metodológica do que estava fazendo, realizei um estudo de caso (que desde sempre se apresentou como único, pois eu não cogitava a existência de estudo de casos múltiplos) sobre um processo legislativo, escolhido pelo critério de ser único e decisivo (Yin, 2005, p. 62). Concretamente, minha pesquisa buscava analisar as discussões parlamentares, e os sentidos subjacentes, que envolveram o processo legislativo que culminou na Lei no 6.683/79 (Lei de Anistia). O problema de pesquisa era identificar o que denominei de discurso de esquecimento que estava amalgamado ao processo de anistia política no Brasil.

De forma despretensiosa, quase que ainda em uma fase exploratória, entrei em contato com a Secretaria de Assuntos Legislativos, do Ministério da Justiça, explicando cuidadosamente que as fontes seriam 
utilizadas uma pesquisa de mestrado, e perguntei se havia registros sobre os debates parlamentares que antecederam a promulgação da Lei n 6.683/79. Fui informada, via e-mail, que meu pedido seria verificado. Surpreendentemente, duas semanas após a realização do meu pedido, recebi um telefonema, por volta de meio-dia, indagando sobre onde me encontrava, pois o material que eu havia solicitado seria entregue pessoalmente. Duas horas depois, recebi duas caixas de transcrições dos debates parlamentares transcorridos entre 1978 e 1979, que tratavam sobre a Lei de Anistia. Nessa parte, indispensável registrar que o Secretário de Assuntos Legislativos da época era Pedro Abramovay, que cursava seu doutorado na mesma universidade que eu e que fazia questão de estreitar os laços entre os debates acadêmicos e as práticas políticas. Não parece ser acaso que naquele momento davam-se os primeiros passos do Projeto Pensando o Direito.

Ato contínuo, analisei as fontes, redigi meu primeiro capítulo - o único reservado à pesquisa empírica. Intuitivamente, talvez por verificar que, de fato, a pesquisa não faria sentido se transcorresse de outro modo, acabei realizando um projeto de pesquisa que, quanto à parte empírica, previa os cinco passos indicados por Yin (2005, p. 42): questões de estudo, proposições, unidades de análise, lógica que une os dados às preposições e critérios para interpretar as constatações. Surpreendentemente, o capítulo que tratava sobre o estudo de caso foi a parte mais rica e instigante de todo o processo de pesquisa e de escrita da dissertação, que até hoje pode ser novamente debatida e problematizada, o que me faz pensar que qualquer outro pesquisador que vier a estudar o mesmo caso, a partir do mesmo questionamento, chegará a constatações semelhantes. Ainda que considerado meu contexto de desconhecimento metodológico, o trabalho realizado parecia-me confiável (Yin, 2005, p. 60).

\section{Plano de vôo II: a necessidade de adoção da pesquisa empírica e o aprofundamento sobre estratégias metodológicas}

Ingressei no doutorado em outra instituição, privada, com um histórico bem distinto daquela em que fiz o mestrado. Embora com outro nome, minha linha de pesquisa foi mantida e o viés transdisciplinar também. No mestrado, havia me debruçado sobre alguns elementos afetos aos Poderes Legislativo e Executivo, o que me levou a ter especial interesse sobre algo que dificilmente aparecia nos debates acadêmicos do meu campo de estudo: o Poder Judiciário. Cabe, aqui, uma breve retomada da contextualização sobre o objeto da pesquisa, pois muitos dos percalços metodológicos são devidos à sua natureza e, a priori, não parece compreensível porque logo o Poder Judiciário não era pautado em uma pesquisa jurídica de campo.

Sinteticamente, a tese se debruçou sobre a atuação e a participação do judiciário brasileiro durante a ditadura civil-militar (1964-1985). O problema era identificar de que forma o judiciário atuou durante os anos de $1964 \mathrm{e}$ 1985, a fim de identificar relações de oposição e solidariedade estabelecidas com o regime militar. A hipótese central era a de que o judiciário assimilou elementos ideológicos do regime militar e naturalizou estruturas e formas de atuação autoritárias. Dentre as variáveis construídas para verificar a hipótese estavam, por exemplo, a utilização da terminologia da Doutrina da Segurança Nacional nas decisões judiciais, a aplicação da legalidade autoritária, a ausência de referência ao contexto sócio-político da época, a estrutura técnico-burocrática da instituição, dentre outros.

Esse estudo utilizaria fontes provenientes da própria instituição, tais como publicações oficiais, transcrições de discursos de posse, atas dos tribunais e fundamentos de decisões judiciais. Como minhas pesquisas há algum tempo se dedicavam ao tema da justiça de transição (transdisciplinar, por excelência), a base teórica para justificar a escolha do objeto e a hipótese de pesquisa não era, de fato, a minha maior preocupação, pois eu já tivera contato com diversos trabalhos que, através de pesquisas empíricas, apresentavam resultados no sentido de que as instituições desempenharam importantes funções na estrutura dos poderes militares na América Latina (Piovesan, 2014). Nesse sentido, os trabalhos de dois pesquisadores estrangeiros, que se valeram de fontes primárias e de estudos comparados para refletir sobre a atuação das instituições durante os regimes autoritários latino-americanos, receberam minha especial atenção: Anthony Pereira e Paloma Aguilar. 
Anthony Pereira (2010) debruçou-se sobre o papel central que determinadas instituições podem assumir em contextos de graves e sistemáticas violações dos direitos humanos. Para ele, as nuanças da relação entre as Forças Armadas e o Judiciário nos regimes militares podem denunciar um tênue vínculo entre a violência passada e presente. A partir de tal constatação, Pereira defendeu em seu trabalho que a relação do Judiciário com as Forças Armadas não é irrelevante, já que os diferentes graus de cooperação e de oposição entre as forças militares e o sistema judicial trazem concretas consequências em relação à efetivação dos direitos humanos. Ademais, para o autor, as decisões proferidas pelos tribunais criam registros históricos, influenciam a sociedade, conferem aparência de legitimidade à legalidade autoritária e moderam a repressão política.

Mencionando o Brasil, Pereira (2010, p. 27) afirma que as instituições legais do regime militar brasileiro deixaram inúmeras consequências, citando que, após 1985, foram fragilizadas as medidas que buscavam instaurar uma justiça de transição, a exemplo da aceitação da autoanistia concedida pela Lei n 6.683/79 e do difícil acesso à documentação em poder dos órgãos de segurança do regime militar.

Já Paloma Aguilar (2013), interessada nas consequências da aliança entre o Judiciário e as Forças Armadas sobre a efetividade de medidas transicionais, fez um estudo comparado entre Chile, Argentina e Espanha. A autora constatou que enquanto o Chile e a Argentina criaram comissões da verdade e revogaram (no caso da Argentina) ou realizaram amplo debate sobre suas leis de autoanistia (no caso do Chile), a Espanha não criou comissões da verdade, não teve nenhum caso de responsabilização judicial, não estabeleceu debate público sobre sua lei de anistia e as decisões judiciais proferidas no regime franquista não foram anuladas.

Analisando os registros sobre a organização judiciária e as decisões proferidas durante os respectivos períodos autoritários, Aguilar (2013, p. 10) constatou que o Judiciário espanhol colaborou com o regime franquista, realizando um controle social e valendo-se da ideologia do regime nas sentenças. Nessa abordagem sobre o relacionamento entre os Poderes Executivo e Judiciário, Aguilar verificou que havia reserva de vagas de ingresso na carreira para juízes partidários do franquis- mo; ampla utilização de sanções disciplinares, recrutamentos, promoções e transferências a fim de limitar a independência dos membros do Judiciário, bem como inúmeros juízes e promotores que integraram tribunais de exceção durante a repressão franquista passaram a ocupar cargos nos alto escalão do Ministério da Justiça e em outros órgãos do Executivo.

Na linha do trabalho de Pereira (2010), Aguilar (2013) formulou a tese de que quanto mais direto o envolvimento do Judiciário na repressão autoritária, menos provável é o estabelecimento de responsabilização judicial ou medidas de verdade durante o período de democratização. Ademais, considerou que quando a responsabilidade pela repressão pode recair sobre membros do Judiciário (não se restringindo apenas às forças militares e policiais), juízes e promotores tendem a relutar em aprovar medidas punitivas contra os repressores. Igualmente, os membros do Judiciário também reagiriam de forma mais incisiva contra a publicização do passado, através de comissões da verdade, pois o escrutínio público no tocante aos atos judiciais poderia denunciar procedimentos realizados sem garantias judiciais mínimas, questionando a lisura e a independência dos órgãos judiciais.

Minha proposta de pesquisa de doutorado sofreu importantes aperfeiçoamentos, a partir de contribuições de professores de outras áreas, principalmente de cientistas políticos e sociólogos. Inspirada nesses aportes e nas pesquisas anteriormente mencionadas, que também possuíam trabalhos com fontes primárias e resultados relevantes e inéditos, defini o plano de trabalho da pesquisa. 0 próximo enfrentamento seria encontrar fontes primárias para a pesquisa nos limites dos deslocamentos possíveis dentro da departamentalização epistemológica de produção do saber jurídico (Machado, 2013, p. 183).

\section{A exploração: a indissociabilidade do amadurecimento da reflexão teórica com a pesquisa de campo}

O problema de pesquisa envolvia dois elementos centrais (ditadura civil-militar brasileira e Poder Judiciário) que deveriam ser concatenados através de conceitos desenvolvidos teoricamente, os quais atuariam como pontes aptas a testar a hipótese de que 
o Judiciário teria atuado de forma solidária com a estrutura autoritária da época. ${ }^{5} \mathrm{O}$ primeiro movimento foi no sentido de identificar as questões relevantes do meu problema de pesquisa, a fim de visualizar quais evidências poderiam responder às suas questões iniciais (Yin, 2005, p. 40). Tratei de revisar a literatura disponível, a fim de desenvolver questões mais objetivas e perspicazes sobre o mesmo tópico. Os resultados dos trabalhos encontrados seriam o ponto de partida da minha pesquisa.

Antes de começar a trabalhar efetivamente com as variáveis teóricas e com a pesquisa de campo, senti a necessidade de tomar algumas decisões metodológicas para delimitar e fundamentar melhor a pesquisa. Quanto ao aspecto territorial, tratei logo de afastar estudos comparados, centrando meu trabalho apenas no Judiciário brasileiro. Ainda assim, para uma só pesquisadora, seria inviável trabalhar com fontes primárias sobre o Judiciário sob um prisma nacional. Trabalharia com um Estado da federação ou mais? Com a justiça comum, especial ou ambas?

Também foi nesse momento, por exemplo, que surgiu o questionamento sobre o que eu entenderia pelo período da ditadura civil-militar: seriam os anos de 1964 até 1985? De 1964 até 1988? Ou de 1946 até 1988, tal como prevê o art. $8^{\circ}$ do Ato das Disposições Constitucionais Transitórias? Ou era razoável construir outro limite temporal? Todas essas possibilidades confrontaram-me com o mais constante desafio da pesquisa empírica: a necessidade de justificar exaustivamente cada elemento utilizado. 0 pesquisador que se propõe a fazer uma pesquisa empírica é constantemente confrontado com sua capacidade de tomar decisões.

Logo após definir o que minha pesquisa interpreta-

5 Convém destacar que tal hipótese foi cuidadosamente construída, sem desconhecimento das inúmeras supressões de garantias dos membros do Judiciário durante a ditadura e de diversos posicionamentos de juízes que publicamente opunham-se ao regime autoritário, os quais, não raras vezes, sofreram represálias pelo poder militar. Ainda assim, feitas essas ressalvas, é possível identificar discursos e comportamentos generalizados dentro da instituição, que fazem com que tais posicionamentos de resistência sejam louváveis exceções diante de um contexto de omissão frente a uma política sistemática e generalizada de graves violações dos direitos humanos. ria como período da ditadura civil-militar, deparei-me com outro desafio: o de encontrar fontes primárias a partir desse limite. Ocorre que, ao tempo desses acontecimentos, não havia certeza sobre a existência e a conservação das fontes primárias que me propunha a utilizar (processos, revistas da época, transcrição de discursos, publicações oficiais em jornais, etc.). Além disso, eu me questionava se, caso elas existissem e estivessem em boas condições de conservação, eu verificaria um processo judicial para cada ano do período ditatorial? Ou seria melhor conjugar a análise de processos com publicações de revistas oficiais? E se um processo durasse oito anos, ele valeria por oito processos? Ou seria melhor considerar o período da ditadura como um macro-limite, sem a preocupação de reiterar a hipótese a cada novo ano? Não haveria risco de concentrar a análise em alguns poucos anos, incorrendo em uma falácia de generalização?

Paralelamente e apesar desses desafios iniciais, em razão da peculiaridade do objeto da pesquisa e do conhecimento sobre o contexto que o envolvia - muito em razão de já pesquisar na área há alguns anos -, percebi que eu deveria manejar meu conhecimento prévio sobre o tema na contramão do que a bibliografia sobre estudo de caso preceitua. Assim, embora já houvesse um razoável desenvolvimento teórico, com a feitura do projeto de pesquisa, antecipei consideravelmente minha fase exploratória, fazendo com que ela se desenvolvesse quase que concomitantemente com o restante da reflexão teórica - contrariando, em alguma medida e justificavelmente, recomendações metodológicas a respeito da delimitação clara de uma teoria antes de iniciar um estudo de caso:

O projeto completo de pesquisa incorpora uma "teoria" do que está sendo estudado. Não se deve, de forma alguma, pensar a respeito dessa teoria como formalidade das grandes teorias em ciências sociais, nem se está pedindo que você seja um teórico magistral. Em vez disso, o objetivo elementar é possuir um esquema suficiente para seu estudo, e isso exige proposições teóricas. Assim, o projeto completo de pesquisa fornecerá uma direção surpreendentemente forte ao determinar quais dados devem ser coletados e as estratégias de análise desses dados. Por essa razão, é essencial que se desenvolva uma 
teoria antes que se faça a coleta de dados para qualquer estudo de caso (Yin, 2005, p. 50).

Provavelmente, em um cenário ideal haveria uma clara delimitação entre a estruturação do projeto, o desenvolvimento da reflexão, a escolha da estratégia metodológica, a coleta dos dados e as conclusões que, no caso, consubstanciaram a tese de doutorado. Entretanto, acolhi a afirmação de Yin (2005, p. 44) sobre a flexibilidade do trabalho, ingressando em uma constante revisitação das unidades de análise. No meu caso, parecia-me que a escolha contrária (que não antecipasse a fase exploratória) poderia prejudicar todo o doutorado.

A preocupação que circundava a proposta de pesquisa empírica era justamente o enigma sobre a existência das fontes primárias e, se existentes, em que medida elas forneciam diagnósticos plausíveis para meus questionamentos. Além disso, na época, não havia nenhuma publicação acadêmica que problematizasse o tema. Era um campo desconhecido. Como dito, o passo seguinte foi investir em uma busca amplamente exploratória, para verificar se tais fontes existiam, quais seus estados de conservação e o que informavam.

Após algumas semanas pesquisando em bibliotecas, para me assegurar sobre o que havia sido publicado sobre o tema, aventurei-me para outros espaços. Obtive, então, o primeiro contato com um terreno razoavelmente desconhecido: os arquivos judiciais. A boa notícia: eles existiam. A má: eram mais de cinco, cada um com diferentes espécies de fontes e, consequentemente, com níveis de informação distintos.

Minha primeira ida, de fato, a um desses lugares poderia integrar um seriado norte-americano de investigação policial: luvas, registros sem flashes, salas à meia luz e, ao invés de cadáveres, páginas amarelas. Ocorrera também um claro confronto com a hermeticidade do direito, pois, desde a primeira visita a esses locais, fui recebida e auxiliada por historiadores, arquivistas, bibliotecários e antropólogos. Não havia nenhum pesquisador do direito e nenhuma pessoa com formação jurídica por perto, à exceção dos diretores dessas instituições que - embora se trate apenas de um palpite -, talvez nunca tivessem manejado aqueles materiais para alguma finalidade (academicamente) produtiva.

Ato contínuo, minha preocupação inicial confirmou-se, em parte. Não existiam mecanismos eficientes de busca dos processos históricos, nem dos outros materiais da época (revistas, panfletos, publicações oficiais, etc.). Verifiquei que, enquanto alguns materiais que haviam tido grande repercussão nos meios de comunicação durante o período da ditadura civil-militar eram cuidadosamente restaurados e arquivados, o restante dos milhões de documentos estava espalhado pelos inúmeros arquivos do Estado e, pior, armazenado das mais variadas maneiras. Começava, então, minha peregrinação por esses locais, os quais me apresentaram as mais variadas formas de guarda de documentos. Algumas, inclusive, com raciocínios e métodos bastante curiosos, relatados a seguir.

Simultaneamente, fui tomada por certo grau de complacência, pois me parecia evidente que, se ninguém fizera as perguntas que constavam no meu projeto de pesquisa, como as respostas poderiam existir? Talvez as dificuldades e os meios heterodoxos de armazenamento das fontes não se restringissem a esse recinto, mas a dificuldade de acesso certamente era potencializada na medida em que as unidades de análise requeriam o cruzamento de informações mais complexas e, sobretudo, inéditas. Constatei que a tecnologia da informação não havia chegado aos meus campos de busca e talvez nem houvesse interesse para tanto. A mim, cabia manejar com engenhosidade o conhecimento sobre as especificidades do meu problema de pesquisa para conseguir acessar algum material que me permitisse visualizá-lo de forma diferente e, sobretudo, responder aos questionamentos de pesquisa.

\section{$5 \quad$ Fazendo uma limonada: dando sentido aos desafios da pesquisa empírica}

Em razão de desconhecer os espaços e os métodos de armazenamento e de seleção dos arquivos, recorria diuturnamente aos profissionais daquelas instituições para melhor compreender a probabilidade de encontrar as fontes adequadas. Em regra, era auxiliada pelos servidores públicos que coordenavam os respectivos arquivos. Durante esse relacionamento, 
mantido concomitantemente com instituições distintas, surgiram alguns percalços, alguns dos quais relato a seguir.

Conforme orientação recebida em um desses casos, eu precisaria ir a três locais diferentes para levantar informações que viabilizassem a busca dos arquivos que procurava. Só então, de posse de cada um desses arquivos, é que verificaria se seus conteúdos serviriam para a pesquisa. Tratava-se, na realidade, de uma caminhada no escuro. Esse percurso triangular deveu-se, em boa parte, pela ausência de digitalização dos processos mais antigos, de forma que os mecanismos naturais de busca utilizados pelos tribunais nos sistemas atuais de pesquisa em jurisprudência não se aplicam aos processos objeto da minha pesquisa. Assim, a busca deveria iniciar em um arquivo de alguma vara judicial, no qual fosse possível encontrar números de processos de determinado período histórico para, só então, tentar encontrar esses processos físicos no Arquivo Judicial Centralizado.

Em outra situação, também acompanhada pelo diretor de um dos arquivos, tive a oportunidade de acessar um programa interno de busca, que me apresentou centenas de fontes aparentemente relevantes para a pesquisa. No dia e no horário agendados para eu ter contato com o material selecionado, descobri que as fontes estavam armazenadas em diferentes caixas. Fui colocada em uma sala com centenas delas, sendo que cada uma das caixas guardava dezenas de outros materiais que não possuíam nenhuma relação com a pesquisa. Minha tarefa, então, era abrir cada caixa e procurar o papel que, em tese, possuísse alguma informação relevante. Após uma semana nesse processo, concluí que essa estratégia de pesquisa não forneceria elementos suficientes para uma pesquisa quantitativa nem fatos relevantes para uma abordagem qualitativa.

Outros fatores curiosos surgiram em meio a essa jornada. Descobri, por exemplo, que coordenadores de instituições distintas não mantinham estreitos laços de amizade, de forma que alguns caminhos de pesquisa que me foram indicados materializavam, na verdade, desavenças pessoais e poderiam ter sido abreviados. Em outras situações, fiz valer a força da argumentação para convencer os profissionais responsáveis pelas fontes que aquelas informações eram relevantes, mesmo que ninguém as tivesse buscado anteriormente. É pertinente destacar, também, que sempre me foi concedido acesso aos arquivos, embora condicionado, em alguns casos, a breves preenchimentos de formulários sobre a Lei de Acesso à Informação.

Gradativamente, passei a interpretar as dificuldades como tensões produtivas que, no mínimo (ou seja, se tudo desse errado), seriam brevemente relatadas em algum lugar da tese para justificar a não realização (ou a frustração) de uma pesquisa empírica. Em meio aos novos espaços e atores, comecei a identificar elementos que, longe de apartarem-se do meu fenômeno de interesse, justificavam, de forma relevante, a dificuldade de encontrar as fontes que poderiam me levar aos resultados esperados. ${ }^{6}$

Descobri, por exemplo, que havia grande quantidade de entrevistas com juízes armazenadas por aqueles arquivos judiciais, o que alguns denominaram de História Oral do Judiciário. Entretanto, também constatei que o objetivo daquele registro oral circunscrevia-se ao relato de vida dos magistrados, de forma que pouco retratava o contexto sócio-histórico do período em que atuavam ou questões polêmicas sobre aplicação do direito ou sobre a atuação do Judiciário enquanto instituição. Esse paradoxo serviu para reiterar alguns indícios obtidos na fase preparatória da pesquisa, ainda restrita às publicações oficiais, sobre meu objeto de pesquisa: a história do Judiciário é institucionalmente confundida (ou fundida) com a trajetória pessoal dos juízes, de forma que há mais informação sobre o número de filhos, a faculdade em que cada qual cursou a graduação em direito e sobre a transferência dos magistrados de comarcas do que acerca do papel que a instituição, Poder Judiciário, exerceu durante 1964 e 1985.

6 Essas dificuldades iniciais contribuíram fortemente para a confecção do artigo "Enquanto isso, na sala da Justiça", vencedor do Concurso de ensaios sobre o tema "Juízes/Judiciário e Ditadura(s) no Brasil", promovido pela Associação Juízes para a Democracia - AJD e pelo Conselho Nacional de Pesquisa e Pós-Graduação em Direito - CONPEDI, cuja premiação foi realizada em novembro de 2013, na Assembleia Ordinária do XXII CONPEDI, em São Paulo. 0 mesmo artigo foi publicado, em versão reduzida, no jornal n $61 \mathrm{da}$ Associação Juízes para a Democracia (Schinke, 2013). 
Ilustrativamente, pode-se citar um livro comemorativo dos 45 anos da Justiça Federal do Estado do Rio Grande do Sul, que abrange o período de 1967-2012, em que não há nenhuma menção ao regime autoritário brasileiro (Rio Grande do Sul, 2012). O mesmo ocorre com diversas outras publicações institucionais da justiça comum estadual, tais como o livro "Tribunal de Justiça do RS - Mais de um Século de História" (Georgiadis, Silveira \& Félix, 2012), que se debruça sobre o período de 1874 a 1999, sem registrar a ditadura militar.

Também detectei que informações objetivas (que notadamente enovelavam a ideia de acesso à justiça com acesso ao Judiciário) eram privilegiadas nas publicações oficiais, de forma que o que me fora apresentado como história oficial do Judiciário possuía duas grandes vertentes: ou relatava a vida dos juízes ou descrevia a criação de varas e comarcas, a transferência de sedes e a criação de justiças especializadas. Meses depois, apurei que aquilo que, inicialmente, se apresentara como um vácuo informativo, caracterizava uma informação nuclear que, possivelmente, justificava fortemente a escolha do objeto e, consequentemente, a relevância da pesquisa. Era, por assim dizer, um silêncio significante.

No início da fase exploratória da pesquisa, tive também contato com um processo em que se buscava a responsabilização de policiais pela prática de tortura e pela morte de um preso político. Essa ação judicial transcorreu por quase todo o período do regime militar brasileiro e foi exaustivamente acompanhada pelos meios de comunicação locais. A instrução desse processo demorou tanto tempo que a autora, viúva do torturado, faleceu antes do trânsito em julgado. A relevância e a riqueza desse processo podem ser apreendidas pelo fato de ter sido tombado, em 2011, e pelo Relatório Final da Comissão Nacional da Verdade tê-lo mencionado como sendo um dos primeiros casos de judicialização das violações ocorridas durante a ditadura civil-militar.

Passados meses de pesquisa em diferentes locais e em contato com diversas fontes, deparei-me, de forma mais contundente, com a necessidade de decidir qual seria a principal estratégia metodológica utilizada na tese e se seria possível, ou conveniente, conjugá-la com outros métodos. Apesar de difíceis, o fato era que havia conseguido fontes relevantes para a pesquisa e que o material me forçava a escolher entre estratégias de pesquisa distintas. Basicamente, parecia-me mais razoável optar entre estudo de caso, incluindo a possibilidade de trabalhar com casos múltiplos, análise de arquivos ou pesquisa histórica.

Em virtude da escassez numérica de fontes da mesma espécie, fortemente ocasionada pelos meios arcaicos de busca nos locais de armazenamento, possibilidades de levantamentos quantitativos foram descartadas. Todavia, além de possuir informações significativas, o material coletado abrangia as mais diversas espécies de fontes, dando conta de diferentes graus e níveis de circulação e de impacto, o que, no fim, também caracterizava um elemento relevante para a pesquisa.

\section{A escolha metodológica: otimizando fontes e conjugando estratégias}

Pode-se dizer que o processo de pesquisa realizado até então, analisado globalmente, considerou todas as técnicas de maneira inclusiva e pluralística (Yin, 2005, p. 36), pois as fontes encontradas tinham as mais diversas origens e forneciam diferentes informações, ou seja, havia grande possibilidade de conjugar mais de uma estratégia metodológica para responder minhas hipóteses.

A estratégia preponderante, ao menos sob o aspecto temporal, em razão da incógnita sobre as fontes, foi o indiciário (Ginzburg, 2007, p. 177), que possibilita a identificação de rastros que integram uma mesma narrativa. Esse método indiciário permite a apreensão de sentidos quando o próprio ato de narrar torna-se falho e omisso. As fontes que demonstram a narrativa institucional do Judiciário sobre si mesmo e a aplicação da legislação autoritária, por exemplo, fornecem elementos aptos para serem trabalhados sob essa perspectiva indiciária.

Recorri a esse paradigma indiciário, pois me pareceu a estratégia mais propícia para compreender formas de controle sociais sutis e minuciosas, a partir de rastros colhidos em diversos materiais, com graus distintos de significação, mas que, ao fim, apontavam 
para uma narrativa relevante dentro do meu problema de pesquisa. De fato, todo o material apreendido trazia indícios de um mesmo comportamento, como se fossem impressões digitais que poderiam me levar a determinada pessoa ou como fragmentos de recortes que viabilizariam formar uma imagem maior.

Se as pretensões de conhecimento sistemático mostram-se cada vez mais como veleidades, nem por isso a ideia de totalidade deve ser abandonada. Pelo contrário: a existência de uma profunda conexão que explica os fenômenos superficiais é reforçada no próprio momento em que se afirma que um conhecimento direto de tal conexão não é possível. Se a realidade é opaca, existem zonas privilegiadas - sinais, indícios - que permitem decifrá-la (Ginzburg, 2007, p. 177).

Paralelamente, houve uma clara possibilidade de unir distintas estratégias metodológicas, a fim de relacionar as fontes com as questões do projeto de pesquisa e de melhor respondê-las. Confeccionei uma árvore metodológica que, embora trabalhosa, unia diferentes estratégias, para melhor atender distintas questões. Registre-se que essa construção só foi viabilizada após o contato com questões teóricas sobre pesquisa empírica, pois, do contrário, eu retornaria ao marco teórico do guarda-chuva. De forma geral, então, a pesquisa somou diferentes estratégias: para problemas inéditos, estratégias criativas.

Considerando que havia um caso (único) que testava minha reflexão teórica, era representativo, revelador e longitudinal (Yin, 2005, p. 63) e que, além de tudo, trava-se de um fenômeno dentro do contexto da vida real, em que os limites entre o fenômeno e o contexto não estavam claramente definidos (Yin, 2005, p. 32), uma das estratégias escolhidas foi o estudo de caso incorporado:

Uma etapa fundamental ao projetar e conduzir um caso único é definir a unidade de análise (ou o próprio caso). É necessária uma definição operacional e devem-se tomar algumas medidas precauções antes que se assuma um compromisso total com o estudo de caso como um todo - para garantir que o caso, na verdade, seja relevante ao tema è̀s questões de interesse. Ainda podem ser acrescentadas subunidades de análises em um caso único, de forma que se possa desenvolver um projeto mais complexo - ou incorporado. As subunidades podem frequentemente acrescentar oportunidades significativas a uma análise extensiva, realçando o valor das impressões em um caso único. No entanto, se for dada atenção demasiada a essas unidades, e se os aspectos holísticos mais amplos do caso começarem a ser ignorados, o próprio estudo de caso terá sua orientação alterada e sua natureza modificada. (Yin, 2005, p. 67)

Concomitantemente, a consciência de que um caso nunca será completo, por si mesmo, forneceu a flexibilidade necessária para combinar essa estratégia com outras abordagens que enriquecessem a reflexão. As fontes colhidas, assim, seriam consideradas na pesquisa para fornecer o contexto para o estudo de caso, para construir uma narrativa indiciária que, ao fim, culminaria no próprio estudo de caso.

Em razão da pesquisa não estar concluída, resta destacar que optou-se por uma estratégia analítica geral com base nas proposições teóricas desenvolvidas ao longo da pesquisa. Tal opção considerou, dentre outros fatores, a extensão temporal do caso, o que tornaria enfadonha uma análise através de estruturas e que, provavelmente, não conduziria claramente às indagações da pesquisa. A análise sobre explanações concorrentes não incidiu na pesquisa. A opção pela análise a partir das proposições teóricas tem se mostrado satisfatória, até então, na medida em que ignora informações irrelevantes para o problema de pesquisa, ao passo que ilumina elementos determinantes. Outro fator positivo é que essa estratégia de análise tem ajudado a organizar todo o estudo de caso (Yin, 2005, p. 168).

A estratégia analítica específica, por sua vez, está baseada na construção da explanação, em razão do forte cunho exploratório da pesquisa (Yin, 2005, p. 149). O constante movimento entre as proposições teóricas iniciais, o caso estudado e a revisitação das proposições teóricas parece ser um pressuposto da própria escolha do problema de pesquisa. Finalmente, o relatório adota o formato clássico de narrativa, concatenando os aspectos estudados no caso com as proposições teóricas. Nesse aspecto, na medida 
do possível, tentei conformar as proposições teóricas com a temporalidade real do caso para facilitar a compreensão do fato, em si, e a relação com o desenvolvimento da reflexão teórica.

\section{Considerações finais}

Este texto afastou-se, consideravelmente, dos formatos tradicionais das narrativas acadêmicas do direito. Com a finalidade de relatar o trajeto de uma pesquisa empírica em direito, ainda em curso, optou deliberadamente por adotar uma forma mais próxima com o leitor, a fim de compartilhar vivências. Não há, todavia, nenhuma pretensão de que os caminhos aqui expostos sejam seguidos por outros pesquisadores. Trata-se, apenas, de contribuir para o debate acerca da construção de novas estratégias metodológicas para produzir conhecimento jurídico. Aparentemente, algumas dificuldades aqui apresentadas podem contribuir para colocar outros pesquisadores do direito de sobreaviso e, no melhor dos casos, confortá-los. Em razão de se tratar de uma narrativa com base em fatos reais, a base teórica apresentada limitou-se a indicar a bibliografia que sustenta a pesquisa, sem tecer considerações sobre leituras anteriores afetas à metodologia jurídica. Como o próprio texto refere, foram realizadas algumas escolhas, inclusive no momento de escrever este texto, no sentido de retratar os elementos que pareciam se diferenciar, mais claramente, de uma pesquisa que se restrinja a considerações dogmáticas.

Nesse ínterim, talvez alguns elementos práticos tenham sido supervalorizados, a exemplo do relacionamento com os diretores dos arquivos. De qualquer forma, o intuito foi transcrever os principais acontecimentos que uma pesquisa empírica que tenta ultrapassar os limites (inclusive físicos) das faculdades de direito pode propiciar. Parece razoável indicar que quaisquer pesquisadores do direito que se proponham a ressignificar a forma pela qual o conhecimento jurídico é produzido, irão ingressar em novos espaços e, necessariamente, dialogar com novos atores e com outros saberes. No mínimo, presume-se que a capacidade de relacionamento interpessoal desses futuros pesquisadores poderá ser aperfeiçoada.

A partir desse relato, constato que a formação aca- dêmica jurídica que privilegia exageradamente métodos estritamente doutrinários, em detrimento de uma amarração com outras técnicas de produção do conhecimento jurídico - mais voltadas à empiria -, contribui diretamente para que fenômenos jurídicos não sejam enfocados sob distintos prismas, fazendo com que partes relevantes de um fenômeno do direito possam permanecer encobertos. Consequentemente, a riqueza que novas técnicas podem acrescentar ao conhecimento do direito é represada. Essa dificuldade de trabalhar com diferentes estratégias de pesquisa pôde ser constatada, nesse texto, pela dificuldade de escolha das estratégias metodológicas e pelos constantes desafios advindos de cada recorte feito na pesquisa. Este relato elucida que algumas dificuldades, aqui relatadas, poderiam ser evitadas se a prática acadêmica colocasse o estudante do direito em contato com as mais variadas metodologias, no intuito de fornecer instrumentos para que, diante de um problema de pesquisa, ele possa realizar escoIhas, de forma consciente e segura, sobre a melhor estratégia a ser adotada.

Como alertado inicialmente, a pesquisa relatada está em curso, o que acarreta que esta narrativa tenha certa propensão à frustração dos seus leitores. De uma forma otimista, prefiro admitir que quem se tenha o trabalho de ler um texto que trate sobre pesquisa empírica em direito abandonou, há muito tempo, qualquer pretensão de completude e de univocidade. Talvez, daqui alguns anos, a pesquisa relatada seja novamente apresentada com os resultados obtidos. Por ora, a única afirmação que pode ser feita, além da que o estudo de caso ainda não está concluído, é a de que o primeiro capítulo da tese é dedicado à estratégia metodológica adotada, vez que os percalços dessa pesquisa empírica podem ser os melhores argumentos para justificar a necessidade de reflexão sobre meu problema de pesquisa.

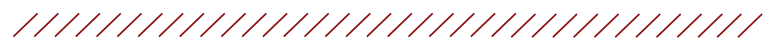




\section{Referências}

Aguilar, P. (2013). Judiciary Involvement in Authoritarian Repression and Transitional Justice: The Spanish Case in Comparative Perspective. International Journal of Transitional Justice, 7 (2), 245-266.

Baumer, F. L. (1990a). O Pensamento Europeu Moderno (v. I). Vila Nova de Gaia. Edições 70.

Baumer, F. L. (1990b). O Pensamento Europeu Moderno (v. II). Vila Nova de Gaia. Edições 70.

Bourdieu, P. (2002). O poder simbólico (5. ed). Rio de Janeiro: Bertrand Brasil.

Brasil (2014). O Judiciário na ditadura. In Comissão Nacional da Verdade, Relatório Final da Comissão Nacional da Verdade (vol I, parte IV, pp. 934-958). Disponível em: http://www.cnv.gov.br/images/ relatorio_final/Relatorio_Final_CNV_Parte_4.pdf

Cooper, H. M. (1984). The integrative research review. Beverly Hills: Sage.

Elster, J. (2006). Rendición de Cuentas - La Justicia Transicional en Perspectiva Histórica. Buenos Aires: Katz.

Georgiadis, C.; Silveira, D. O.; Félix, L. O. (2012). Tribunal de Justiça do RS - Mais de um Século de História. Memorial do Judiciário do RS. Porto Alegre: Departamento de Artes Gráficas do TJ.

Ginzburg, C. (1987). O queijo e os vermes: o cotidiano e as idéias de um moleiro perseguido pela Inquisição (3. ed). São Paulo: Companhia das Letras.

Ginzburg, C. (2007a). Mitos, emblemas, sinais: morfologia e história (2. ed). São Paulo: Companhia das Letras.

Ginzburg, C. (2007b). O fio e os rastros: verdadeiro, falso, fictício (2. ed). São Paulo: Companhia das Letras.

Habermas, J. (2009). A Lógica das Ciências Sociais. Petrópolis: Vozes.

Koselleck, R. (2006). Futuro passado: contribuição à semântica dos tempos históricos. Rio de Janeiro: Contraponto.

Lima, R. K. (1997) A antropologia da academia: quando os índios somos nós (2. ed). Niterói: EDUFF.

Mate, R. (2005). Memórias de Auschwitz - atualidade e política. São Leopoldo: Nova Harmonia.

Mate, R. (2008a). La herencia del olvido. Madrid: Errata naturae editores.

Mate, R. (2008b). La razón de los vencidos. Barcelona: Anthropos Editorial.

Martins, G. A. (2008). Estudo de Caso: uma estratégia de pesquisa (2. ed). São Paulo, Atlas.

Pereira, A. (2010). Ditadura e repressão: o autoritarismo e o Estado de Direito no Brasil, no Chile e na Argentina (Trad. P. de Q. C. Zimbres). São Paulo: Paz e Terra.

Piovesan, F. (2014). Justiça de transição, reformas institucionais e consolidação do Estado Democrático de Direito: o caso brasileiro. In E. P. Meyer \& A. C. Oliveira. Justiça de transição nos 25 anos da Constituição de 1988 (2. ed). Belo Horizonte: Initia Via.

Ricoeur, P. (2007). A memória, a história, o esquecimento. Campinas: Editora da Unicamp.

Rio Grande do Sul (2012). 1967-2012: JFRS 45 anos em movimento. Primeira Instância, 227.

Santos, R. L. (2010). Crimes da ditadura militar - responsabilidade internacional do Estado brasileiro por violação aos Direitos Humanos. Porto Alegre: Nuria Fabris.

Schinke, V. D. (2013). Enquanto isso, na sala da Justiça. Juízes para a Democracia, 14 (61), 10.

Seligmann-Silva, M. \& Nestrovski, A. (2000). Catástrofe e Representação. São Paulo: Escuta.

Seligmann-Silva, M. (2008). Narrar o trauma: a questão dos testemunhos de catástrofes históricas. In R. K. Umbach (Org.) Memórias da repressão. Santa Maria: UFSM, PPGL.

Stake, R. E. (2009). A arte da investigação com estudos de caso (2. ed). Lisboa: Calouste Gulbenkian.

Teitel, R. (2003). Transitional Justice Genealogy. Harvard Human Rights Journal, 16, 70-94.

Todorov, T. (2000). Los abusos de la memoria. Barcelona: Paidós.

Wolcott, H. F. (1990). Writing up qualitative research. Newbury Park: Sage.

Yin, R. (1997). Case study evaluations: a decade of progress? New Directions for Evaluation, 76, 69-78.

Yin, R. (2005). Estudo de caso: planejamento e métodos. 3. ed. Porto Alegre: Bookman.

Zyl, P. V. (2009). Promovendo a justiça transicional em sociedades pós-conflito. Revista Anistia Política e Justiça de Transição, 1 (jan./jun.), 32-55.

Data de submissão/Submission date: 30.09 .2014

Data de aceitação para publicação/Acceptance date: 21.12.2014 